\title{
TRATAMENTO DE DENTES COM RECESSÃO GENGIVAL E ABRASÃO CERVICAL
}

\author{
Lyla Prates de Andrade Especialista em Periodontia pela \\ Escola Bahiana de Medicina e Saúde \\ Pública
}
Adriana Biscarde Especialista em Periodontia pela Escola Bahiana de Medicina e Saúde Pública

\begin{abstract}
Alexandre Moreira Mestre em Laser pela USP. Professor do Curso de Odontologia da Escola Bahiana de Medicina e Saúde Pública

Érica Ribeiro Mestre e doutor em Periodontia pela Universidade de Campinas. Professor do Curso de Odontologia da Escola Bahiana de Medicina e Saúde Pública

Sandro Bittencourt Mestre e doutor em Periodontia pela Universidade de Campinas. Professor do Curso de Odontologia da Escola Bahiana de Medicina e Saúde Pública
\end{abstract}

\begin{abstract}
Resumo
Objetivo: Revisar a literatura e apresentar um caso tratado com uma abordagem restauradora e periodontal integrada. Descrição do caso: O tratamento de uma recessão classe III de Miller com abrasão cervical no canino superior esquerdo, a qual foi previamente restaurada com resina composta e recoberta com enxerto de tecido conjuntivo subepitelial, mostrou melhora da hipersensibilidade e estética com ausência de sinais de inflamação. Conclusão: A recessão gengival classe I e II de Miller com abrasão cervical pode ser tratada com sucesso combinando a restauração do defeito com o recobrimento radicular. Contudo, são necessários mais estudos para confirmar esses resultados.
\end{abstract}

Palavras-chave: Recessão gengival. Retalho cirúrgico. Abrasão dentária.

TREATMENT OF GINGIVAL RECESSION WITH CERVICAL ABRASION

\begin{abstract}
Purpose: To review the literature and show a case treated by an integrated restorative and periodontal approach. Case description: A treatment of a Miller Class III gingival recession associated with cervical abrasion on his maxillary left canine, which was previously restored with resin composite and covered by a subepthelial connective tissue graft showed improvement of the hypersensitivity and esthetics with no signs of gingival inflammation. Conclusions: The Miller Class I and II gingival recession with cervical abrasion can be successfully treated associating the defect restoration with the root recover. However, it's necessary more studies to support these positive results.
\end{abstract}

Keywords: Gingival recession; Surgical flap; Tooth abrasion.

Revista Bahiana de Odontologia, Salvador, dez. 2012; 3(1): 86-99.

http://www.bahiana.edu.br/revistas 


\section{INTRODUÇÃO}

A recessão gengival pode ser caracterizada como o deslocamento apical da margem gengival em relação à junção cemento esmalte $(\mathrm{JCE}),{ }^{(1,2)}$ com consequente exposição da superfície radicular. ${ }^{(3)}$

A etiologia da recessão gengival não é conclusiva, já que um fator pode ser o principal, mas não o único aspecto a causar essa alteração. ${ }^{(3)}$ Diversos fatores etiológicos são atribuídos a essa condição clínica, como hábitos de higiene oral, má posição dentária, inserção anormal de bridas e freios, deiscências ósseas, fatores iatrogênicos relacionados a procedimentos restauradores e ortodônticos e doença periodontal. ${ }^{(1,4)}$ Porém, eles podem ser divididos em dois grupos: fatores precipitantes ou primários, que induzem diretamente a recessão gengival e fatores predisponentes, que favorecem a área ao seu acometimento. ${ }^{(3)}$ Os fatores etiológicos primários são o acúmulo de placa com a resultante doença periodontal inflamatória e o trauma mecânico associado à técnica de higiene oral inadequada. ${ }^{(1)}$

Recessão gengival é uma característica comum na maioria das populações, tanto em países desenvolvidos quanto em subdesenvolvidos, podendo ser encontrada em qualquer idade. ${ }^{(1)} \mathrm{A}$ prevalência, extensão e severidade da recessão aumentam gradualmente com a idade, sugerindo-se o efeito acumulativo por um longo período de exposição aos agentes etiológicos como causa. ${ }^{(3)} \mathrm{A}$ prevalência da recessão gengival entre os dentes mais afetados diferem entre os estudos populacionais, não havendo consenso na literatura. Contudo, a face vestibular dos dentes é unanimemente indicada como sítio mais afetado por essa alteração, sendo o trauma de escovação a causa mais associada. ${ }^{(1)}$ Já nas faces lingual e interproximais, a recessão está associada a pobres hábitos de higiene oral. ${ }^{(1)}$

Devido a exposição radicular, esse defeito antiestético pode causar hipersensibilidade dentinária e propiciar as lesões de cárie de raiz e lesões cervicais não cariosas, como a abrasão cervical ${ }^{(3)}$ consequências que indicam o recobrimento radicular como tratamento da recessão gengival.

Abrasão cervical é a perda patológica de estrutura dental resultante de desgaste biomecânico, que pode ocorrer na região cervical dos dentes como consequência de escovação excessiva ou inadequada.${ }^{(5)}$ Contatos oclusais deletérios podem provocar desgastes radiculares, as abfrações, que, na maioria das vezes, estão também associadas ao trauma de escovação. ${ }^{(5)}$ Superfícies abrasionadas têm uma aparência lisa e polida, que raramente apresentam acúmulo de placa ou cárie, ${ }^{(5)}$ e frequentemente se estendem apicalmente à margem gengival livre. ${ }^{(6)}$ Lesões de abrasão inicialmente aparecem como uma pequena e horizontal canaleta ao longo da superfície vestibular da raiz natural, próxima a JCE. ${ }^{(5)}$

Recessão gengival associada à abrasão cervical é muito comum. ${ }^{(7,8)}$ Dentre os 900 dentes com recessão gengival examinados em seu estudo, Zucchelli, Testori e Sanctis ${ }^{(7)}$ encontraram abrasão associada à mais de $90 \%$ das recessões. Pode-se especular que o fator etiológico como o trauma de escovação pode ter ocorrido na região cervical do dente, causando inicialmente recessão gengival e

Revista Bahiana de Odontologia, Salvador, dez. 2012; 3(1): 86-99. 
depois a abrasão dental. ${ }^{(7)}$ É altamente improvável que esse trauma fique limitado à área da raiz exposta, ele provavelmente envolve toda a região cervical, portanto, ambos o esmalte e o cemento, ocasionando o desaparecimento da JCE. ${ }^{(4,7)}$

A primeira etapa do tratamento dessa condição clínica deve ser a eliminação e controle de todos os fatores etiológicos potenciais relacionados com a causa da recessão gengival e abrasão cervical, ${ }^{(4,9)}$ etapa da qual depende o sucesso e a longevidade do tratamento. ${ }^{(4)}$

A seleção do plano de tratamento depende das características anatômicas locais, como a altura e a profundidade da lesão cervical não cariosa, a extensão das áreas de coroa e raiz afetadas pelo defeito, a altura da recessão gengival, a presença de tecido queratinizado apical ao defeito e as expectativas estéticas do paciente. ${ }^{(4)}$

Muitas cirurgias de recobrimento radicular são propostas com sucesso para o tratamento da recessão gengival, assim como muitos materiais restauradores são propostos para a reconstrução do tecido duro, porém existem poucos relatos na literatura sobre uma abordagem combinada, apesar da próxima relação entre recessão e abrasão. Apenas a restauração do defeito, não resolve a queixa estética do paciente, pois resultará em um dente excessivamente longo. ${ }^{(4,6,7)}$ Da mesma forma, se a terapia mucogengival para recobrimento radicular for realizada individualmente, a abrasão pode não ser totalmente recoberta e a hipersensibilidade dentinária pode persistir, ${ }^{(4)}$ além de comprometer também a harmonia estética.

A presença de recessão gengival Classe I e II de Miller associada com abrasão cervical pode requerer então cirurgia periodontal combinada com tratamento restaurador. ${ }^{(2,4,6,7)} \mathrm{O}$ preenchimento do defeito torna a superfície radicular mais adequada para o procedimento cirúrgico mucogengival de recobrimento devido à restauração do perfil de emergência do dente, o que promove uma estável, lisa e convexa substância dura para o posicionamento do retalho, além de facilitar o controle de placa do paciente. $^{(7)}$

O recobrimento radicular pode ser realizado isoladamente no tratamento de recessões com abrasões rasas de até $1,0 \mathrm{~mm}$ de profundidade. ${ }^{(4)}$ Nesses casos, a concavidade da lesão pode ser eliminada através do aplainamento radicular com instrumentos manuais ou brocas diamantadas de acabamento em alta rotação, com o intuito de promover uma melhor adaptação do retalho. ${ }^{(4)}$

Uma abrasão profunda pode criar um espaço morto entre a superfície radicular e o tecido conjuntivo do retalho, comprometendo a sua adaptação. ${ }^{(4)}$ Portanto, faz-se necessária a restauração de tais defeitos previamente à cirurgia periodontal.

O trauma de oclusão também deve ser avaliado nesse tratamento combinado, pois pode haver associação de abfração com a abrasão cervical, e esse problema pode levar ao fracasso da restauração do defeito. ${ }^{(5)}$

Foram propostas as características ideais dos materiais restauradores usados em lesões subgengivais: biocompatibilidade, um sistema de polimerização dual, adesividade, liberação de flúor, 
radiopacidade, compactação, resistência de superfície, insolubilidade aos fluidos orais, ausência de microinfiltração, baixo coeficiente de expansão térmica e baixa contração de polimerização. ${ }^{(10)}$

Dragoo $^{(10)}$ afirmou que as restaurações subgengivais podem ser realizadas mais rotineiramente, graças aos materiais com capacidades adesivas e com biocompatibilidade com os tecidos circunjacentes, como certos ionômeros resinosos restauradores. ${ }^{(10)}$ Evidências histológicas demonstraram adesão dos tecidos epitelial e conjuntivo às restaurações de ionômero resinoso durante a cicatrização tecidual, após recobrimento radicular. ${ }^{(10)}$

Existem relatos de resultados positivos com o uso de ionômero de vidro resinoso modificado $(2,4,6,8,10,11)$ e resina composta microparticulada ${ }^{(6,8,11)}$ em restaurações de lesões cervicais recobertas, sem sinais de inflamação, acúmulo de placa ou formação de bolsa periodontal, desde que o paciente mantenha um ótimo controle de placa e as restaurações tenham contorno e acabamento adequado. ${ }^{(6)}$ Além disso, o controle da técnica restauradora (uso do isolamento absoluto e controle do tempo de fotopolimerização) é essencial para o sucesso dessa abordagem, ${ }^{(6,11)}$ pois a saúde periodontal é dependente do apropriado planejamento restaurador. ${ }^{(12)}$

Embora transgengivais, é válido ressaltar que a margem apical de todas as restaurações deve ter a distância mínima de $3 \mathrm{~mm}$ da crista óssea, garantindo a estabilidade do espaço biológico e a saúde periodontal. ${ }^{(12)}$

Duas técnicas cirúrgicas foram propostas com sucesso para o recobrimento radicular de recessões gengivais com lesões cervicais restauradas: o retalho reposicionado coronalmente ${ }^{(4,6,11)}$ e o enxerto de tecido conjuntivo subepitelial, ${ }^{(2,4)}$ comumente associado ao retalho reposicionado coronalmente.

No estudo de Lucchesi et al., ${ }^{(6)}$ de seis meses de acompanhamento, todos os tratamentos mostraram êxito no recobrimento radicular sem prejuízo aos tecidos periodontais, sustentando o uso do retalho reposicionado coronalmente para o tratamento de superfícies radiculares restauradas com ionômero de vidro resinoso modificado e resina composta microparticulada, com uma percentagem de recobrimento de $71,99 \%$ e 74,18\% respectivamente e no grupo controle (raízes intactas) de $80,83 \%{ }^{(6)}$ Então, considerando-se a média de redução de recessão, a presença de resina composta microparticulada e ionômero de vidro resinoso modificado não diminui a previsibilidade do retalho reposicionado coronalmente. ${ }^{(6)}$

Segundo Santos et al., ${ }^{(11)}$ o recobrimento radicular de recessões gengivais associadas às lesões cervicais não cariosas restauradas com ionômero de vidro resinoso modificado e resina composta microparticulada também foi similar ao resultado encontrado nas superfícies radiculares intactas, após a cirurgia com retalho reposicionado coronalmente observado por 6 meses. ${ }^{(11)}$ Entretanto, o ionômero de vidro resinoso modificado parece exercer mais resultados positivos na composição do biofilme subgengival do que a resina composta microparticulada. ${ }^{(1)}$

Revista Bahiana de Odontologia, Salvador, dez. 2012; 3(1): 86-99. 
Recessões moderadas podem ser tratadas com retalho reposicionado coronalmente e recessões largas e/ou profundas necessitam de enxerto de tecido conjuntivo. ${ }^{(13)}$ Em casos de abrasão cervical não restaurada, o enxerto de tecido conjuntivo pode melhor se adaptar para evitar o colapso do retalho na superfície radicular e promover uma melhor reparação da morfologia do tecido mole. ${ }^{(13)}$

O percentual de recobrimento de uma superfície radicular previamente exposta é o primeiro resultado clínico usado para avaliar a efetividade do procedimento mucogengival, ${ }^{(6)}$ sendo necessária, para isso, a identificação da JCE ${ }^{(7)}$ Contudo, nos casos de abrasão cervical associada à recessão, a JCE não pode ser clinicamente detectável, podendo ser confundida com a linha que separa o esmalte da dentina exposta. ${ }^{(7)}$ Portanto, devido à maioria das margens coronais das lesões provavelmente encontrarem-se acima da JCE, um percentual menor de dente-restauração recoberto é esperado ${ }^{(6)}$ e a dentina exposta ou restauração supragengival pós-cirúrgica não devem ser erroneamente consideradas como insucesso da técnica cirúrgica de recobrimento radicular. ${ }^{(7)}$

A cirurgia periodontal associada com o procedimento restaurador promove solução para ambos os defeitos, gengival e dental. ${ }^{(4)}$ Entretanto, é importante notar que existem limitações no recobrimento radicular e que, dessa forma, essa abordagem combinada deve ser realizada apenas onde as características locais permitam um prognóstico favorável. ${ }^{(4)} \mathrm{A}$ classificação de Miller é conveniente na avaliação do prognóstico do recobrimento radicular, ${ }^{(13)}$ sendo favoráveis às recessões classe I e II. ${ }^{(3)}$ Além da perda óssea interproximal e ausência de tecido queratinizado, perda em altura da papila interdental, abrasão oclusal, giroversão e extrusão dental devem ser consideradas, pois são fatores que podem limitar o completo recobrimento radicular. ${ }^{(7)}$

Devido à alta prevalência de recessão gengival com abrasão cervical e a escassez de evidências literárias sobre essa associação, o objetivo deste trabalho é revisar a literatura e apresentar um caso clínico tratado com uma abordagem restauradora e periodontal integrada.

\section{DESCRIÇÃO DO CASO}

Um paciente de 38 anos, sexo masculino, foi encaminhado para a Especialização em Periodontia do Curso de Odontologia da Escola Bahiana de Medicina e Saúde Pública com queixa de hipersensibilidade e estética no canino superior esquerdo. Após exame clínico, constatou-se a presença de recessão gengival Classe III de Miller associada à abrasão cervical profunda (Figura 1).

Revista Bahiana de Odontologia, Salvador, dez. 2012; 3(1): 86-99. 


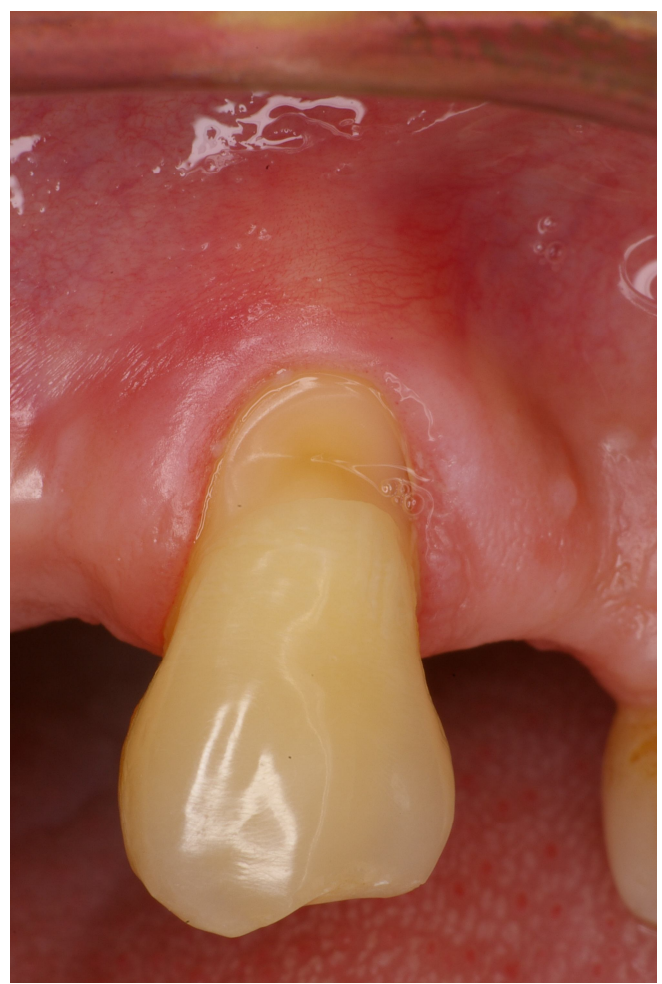

Figura 1 - Unidade 23 apresentando recessão gengival Classe III de Miller associada à desgaste cervical

O plano de tratamento consistiu no preenchimento do defeito e posterior recobrimento radicular com enxerto de tecido conjuntivo em microcirurgia.

Inicialmente foram feitas: instrução de higiene oral, com mudança da técnica de escovação para evitar novos traumas; raspagem e alisamento radicular; e restauração com resina composta microparticulada da lesão cervical de abrasão (Figura 2). 


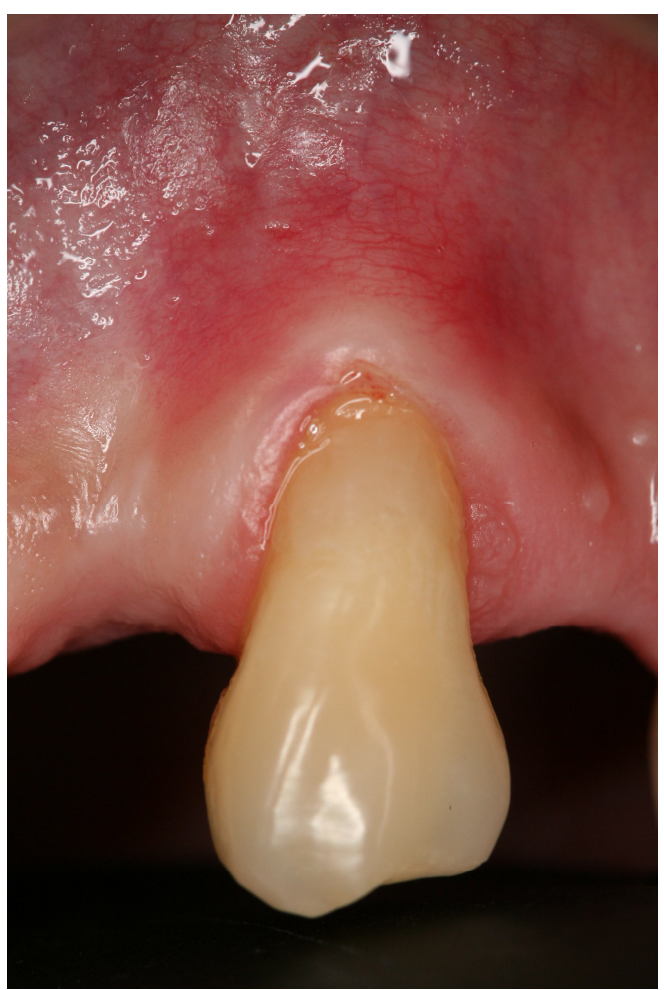

Figura 2 - Unidade 23 após restauração com resina fotopolimerizável

O procedimento restaurador foi realizado por um aluno da Clínica Integrada I do Curso de Odontologia da EBMSP. Sob anestesia local, iniciou-se o procedimento com o acabamento da restauração com broca multilaminada (Figura 3) e cureta mini-five Gracey n ${ }^{\circ}$ 5/6 da Hu-friedy. Foram realizadas incisões de microcirurgia periodontal. ${ }^{(19)}$ 


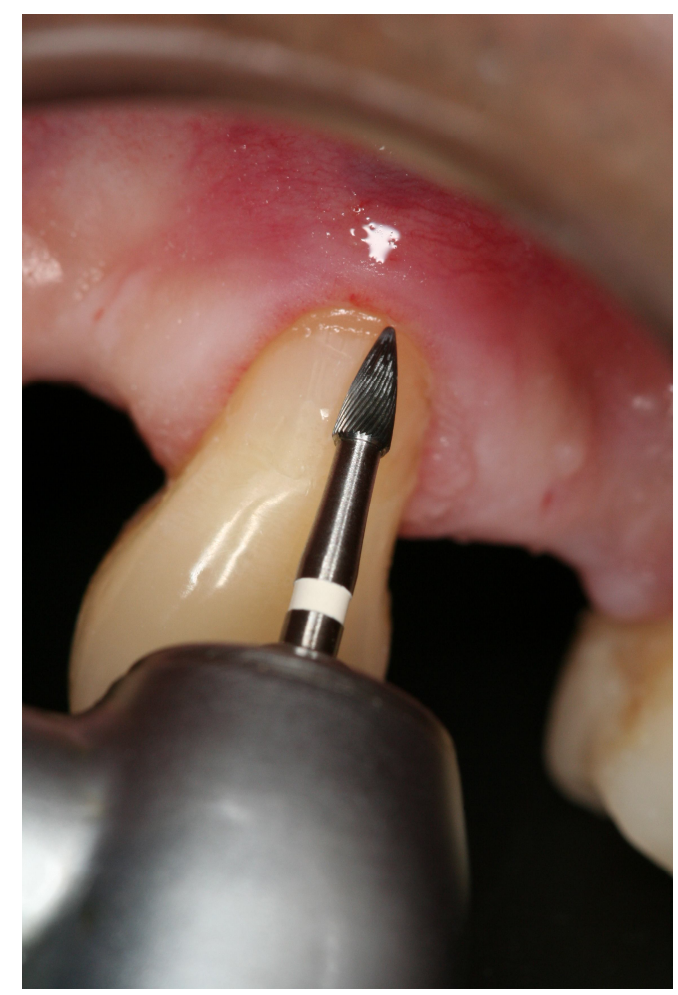

Figura 3 - Broca multilaminada utilizada para acabamento da restauração

Um retalho parcial foi dividido até obter mobilidade satisfatória e os tecidos entre as incisões foram desepitelizados. O leito receptor foi então medido, do centro da papila mesial ao centro da papila distal, com uma sonda periodontal manual, (Figura 4) e a medida foi transferida para a área doadora. Com bisturi de lâmina dupla, removeu-se um enxerto de tecido conjuntivo de $1 \mathrm{~mm}$ de espessura do palato do paciente. $\mathrm{O}$ enxerto foi adaptado no leito receptor e imobilizado através de uma sutura contínua de aproximação com fio reabsorvível Vicryl 6.0. Algumas suturas interrompidas de coaptação foram realizadas com fio reabsorvível Vicryl 8.0 (Figura 5). A ferida do palato foi fechada com uma sutura contínua com o fio Vycril 6.0. 


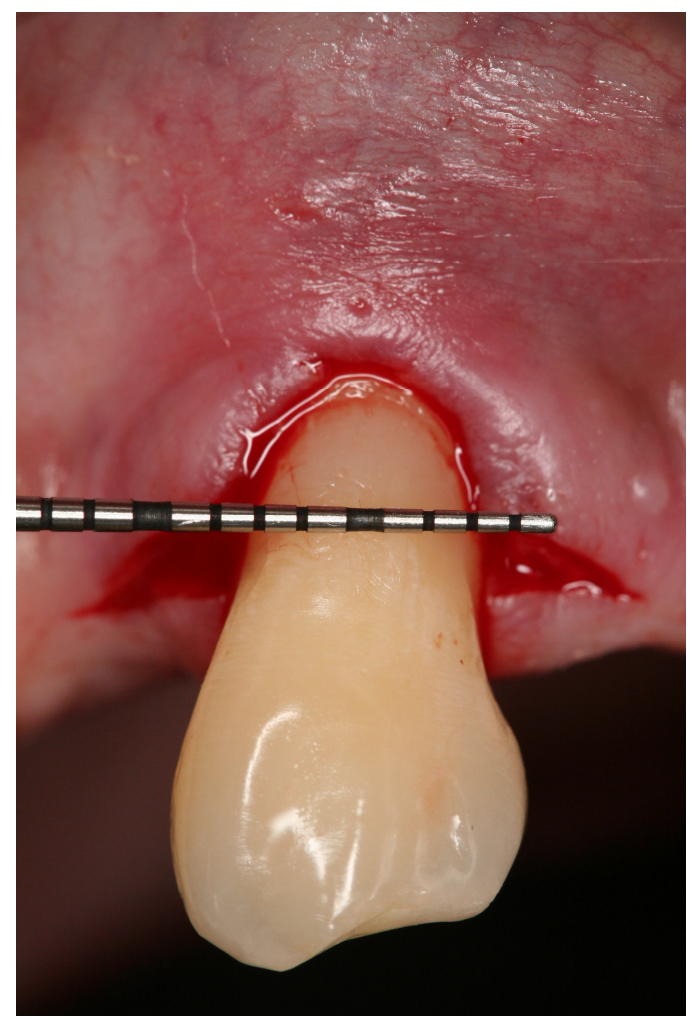

Figura 4 - Sonda milimetrada mensurando o tamanho do enxerto conjuntivo subepitelial a ser retirado

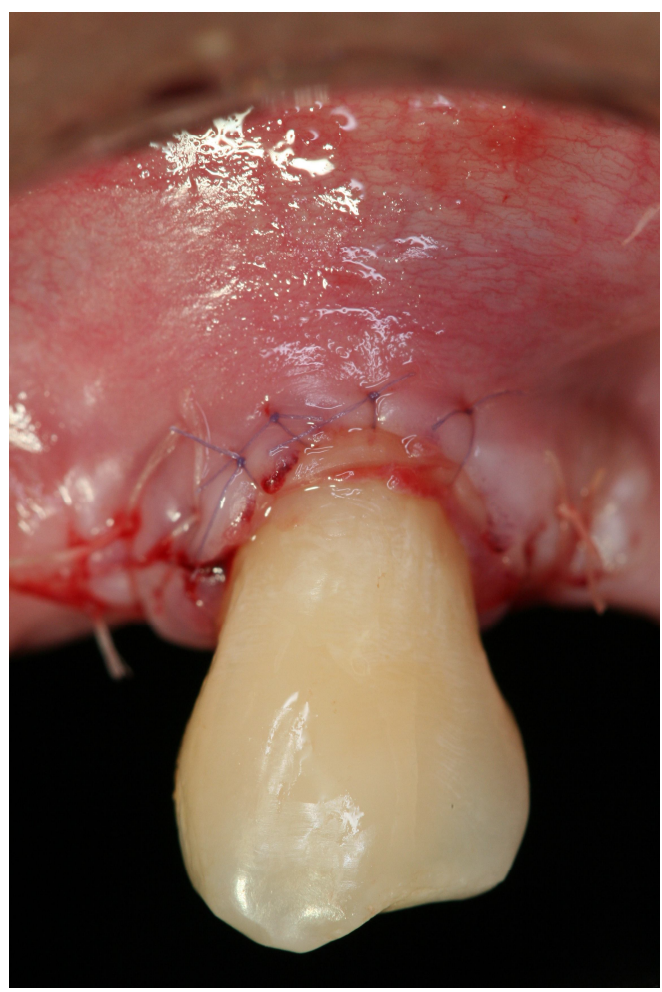

Figura 5 - Suturas de aproximação e coaptação 
Como medicação pós-cirúrgica, foram prescritos anti-inflamatório não esteroide (diclofenaco sódico - $50 \mathrm{mg}$ ) por três dias e analgésico (dipirona sódica - $500 \mathrm{mg}$ ) em caso de dor. O paciente foi instruído a não escovar a região por quatro semanas e a usar nesse período o bochecho de clorexidina a $0,12 \%$, duas vezes ao dia, para controle de placa.

Foram marcadas avaliações semanais no $1^{\circ}$ mês e posteriormente mensais. As suturas da área doadora foram removidas com sete dias e da área receptora com quinze dias (Figura 6). Embora não tenha havido um recobrimento radicular considerável, devido ao tipo da recessão, o paciente relatou melhora na hipersensibilidade e após as quatorze semanas de acompanhamento, clinicamente foi encontrada saúde gengival, sem sinais de inflamação (Figura 7).

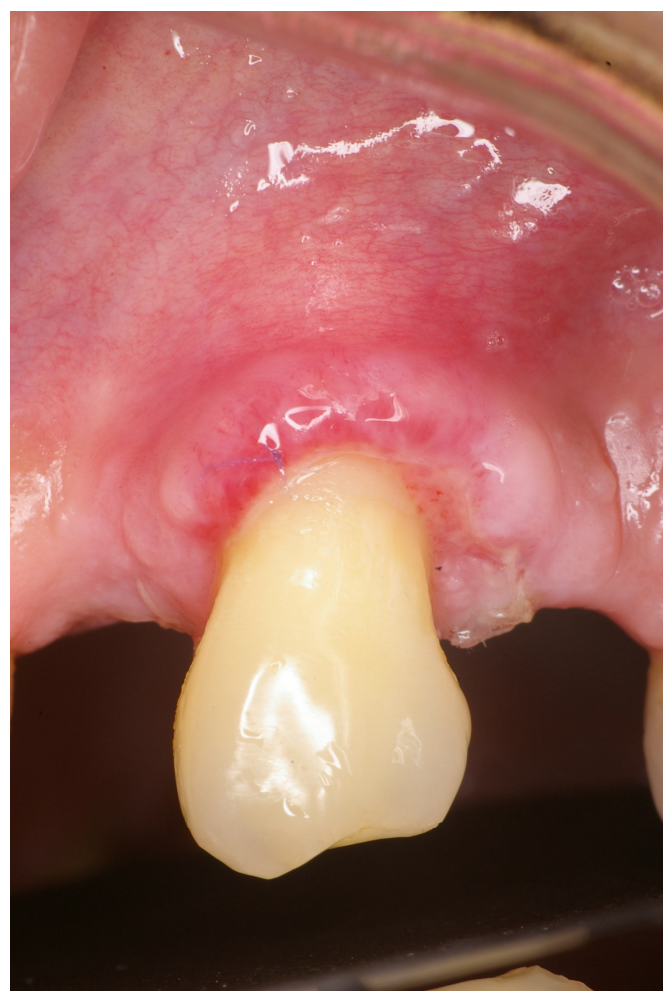

Figura 6 - Pós-operatório de 15 dias 


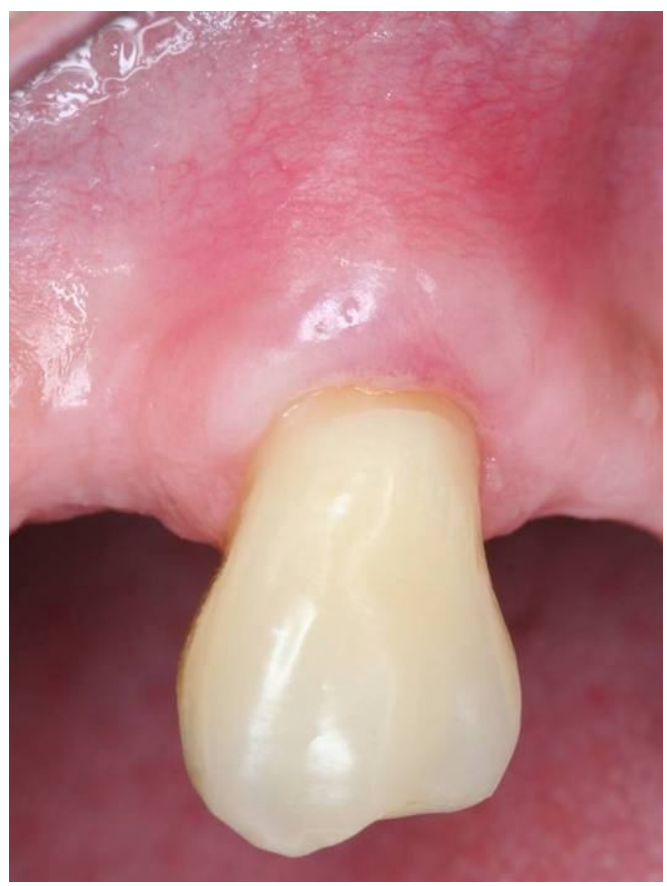

Figura 7 - Pós-operatório de 14 semanas

\section{DISCUSSÃO}

Embora os periodontistas prefiram margens das restaurações supragengivais, entende-se que certas condições, como estética, necessidade de aumentar retenção, cáries radiculares, abrasão cervical e sensibilidade radicular, necessitam a colocação das margens transgengivais. ${ }^{(12)}$

Em abrasões cervicais profundas, como no caso relatado neste trabalho, a restauração associada ao recobrimento radicular é indispensável, pois o defeito causaria prejuízo na adaptação do retalho sobre a superfície radicular e apenas um aplainamento seria inviável devido à grande quantidade de tecido sadio que teria que ser removida. ${ }^{(4)}$ Além disso, o desgaste cervical estendia-se à coroa do dente, impossibilitando o seu recobrimento completo, o que, na ausência da restauração, poderia dificultar o controle de placa, a solução à hipersensibilidade e estética.

Além da profundidade da lesão cervical não cariosa, a sua forma deve ser levada em consideração no plano de tratamento, já que os defeitos em cunha, com ângulos retos, apresentam-se como um degrau favorável a impacção alimentar. Então, mesmo rasos, tais defeitos cervicais devem ser restaurados.

Apesar de terem sido encontrados neste trabalho bons resultados no recobrimento radicular de superfície restaurada, sem danos aos tecidos periodontais, assim como relatado em outros estudos, ${ }^{(2,4,6,10,11)}$ Padbury et al. (2003) sugerem que mesmo a mínima invasão dos tecidos subgengivais pode levar a efeitos deletérios no periodonto. ${ }^{(12)}$ 
Desde os estudos de Dragoo, ficou estabelecido a biocompatibilidade do cimento de ionômero de vidro. ${ }^{(14)}$ Entretanto, na busca de uma resolução mais estética, estudos com novos materiais foram publicados, ${ }^{(6,8,11)}$ como é o caso da resina composta microparticulada, usada no caso clínico apresentado. Essa resina tem propriedades que permitem um melhor acabamento e polimento, provendo uma superfície mais lisa e polida e assim um melhor resultado quanto à estética e ao controle de placa.

Objetivando avaliar as vantagens desse material restaurador, Lucchesi et al. ${ }^{(6)}$ e Santos et al. ${ }^{(1)}$ encontraram, no recobrimento radicular de recessões gengivais, resultados clínicos similares nas abrasões restauradas com resina composta microparticulada e nas superfícies radiculares intactas, sem sinais de inflamação, em acompanhamento de 6 meses. ${ }^{(6,11)}$ Porém, de acordo com resultados microbiológicos, a resina mostrou algum efeito negativo na composição do biofilme subgengival, com uma proporção de Fusobacterium nucleatum polymorphum significantemente maior após o período de observação. ${ }^{(11)}$

Martins et al., ${ }^{(8)}$ em um estudo histológico em cães, usaram cimento de ionômero de vidro resinoso modificado e resina composta microparticulada em restaurações recobertas. ${ }^{(8)}$ Esses materiais usados subgengivalmente mostraram-se biocompatíveis, contudo, ambos interferiram no processo de cicatrização periodontal, já que houve formação de epitélio juncional longo sobre as restaurações e não desenvolvimento de novo osso e inserção conjuntiva ${ }^{(8)}$ como relatado por Dragoo. ${ }^{(10)}$ Porém, vale ressaltar que os defeitos foram produzidas artificialmente, ${ }^{(8)}$ sem o limite mínimo de $3 \mathrm{~mm}$ de distância da crista óssea. ${ }^{(12)}$

No seu relato de três casos clínicos de restauração de abrasão cervical, com ionômero de vidro resinoso modificado, associada ao recobrimento radicular com retalho reposicionado coronalmente ou enxerto de tecido conjuntivo subepitelial, Santamaria et al. ${ }^{(4)}$ relataram resultados similares entre as técnicas e sucesso em ambos os tratamentos, após oito meses de avaliação.

O caso deste relato foi tratado com enxerto de tecido conjuntivo devido à sua alta previsibilidade frente à presença de restauração cervical, citada por Gray ${ }^{(9)}$ como uma dificuldade ao procedimento, pois uma superfície radicular biologicamente aceitável é um pré-requisito para o recobrimento radicular. Bouchard et al. ${ }^{(13)}$ afirmaram que o enxerto de tecido conjuntivo subepitelial tem melhor prognóstico em função do duplo suprimento sanguíneo provido pelo retalho que o recobre e pelo tecido conjuntivo periosteal do leito, sendo atualmente a referência para estudos prospectivos comparativos no uso das várias técnicas de recobrimento radicular. ${ }^{(13,14)}$

Assim como sugerido por Bouchard et al., ${ }^{(13)}$ no caso descrito no presente estudo, foram realizadas incisões horizontais, a fim de evitar linhas de cicatriz pós-operatória causadas por incisões verticais ou relaxantes e permitir melhor revascularização à área do enxerto.

O planejamento da microcirurgia periodontal deve-se ao fato da abordagem microcirúrgica promover mais rápida cicatrização e um excelente resultado estético no tratamento de recessão 
gengival. ${ }^{(15)}$ Segundo Campos et al., ${ }^{(15)}$ a iluminação e magnificação da área cirúrgica proporcionada pelo microscópio e o uso dos instrumentais de microcirurgia permitem melhor acuidade visual, que resulta na realização de um procedimento muito mais preciso.

Embora o recobrimento aparentemente não ter sido completo, o seu resultado foi favorável, já que se tratava de uma recessão classe III de Miller em função da perda dos dentes adjacentes, e, portanto, tinha uma previsibilidade de recobrimento reduzida. ${ }^{(3)}$ Além disso, a parte de restauração exposta já era esperada, devido à perda de esmalte cervical pela desgaste cervical. ${ }^{(7)}$

Santamaria et al. ${ }^{(4)}$ afirmam que a cirurgia periodontal combinada com o procedimento restaurador resolve ambos os defeitos gengival e dental em uma única sessão, concordando com Alkan et al. ${ }^{(2)}$ Apesar disso, outros autores relataram a realização da restauração cervical previamente ao ato cirúrgico, ${ }^{(6,11)}$ ou seja, em duas sessões, como apresentado nesse caso. Mesmo com uso do isolamento absoluto, é mais difícil manter o campo seco, essencial para o procedimento restaurador, durante a cirurgia. Sendo assim, a restauração trans-cirúrgica está mais indicada em casos em que, em campo fechado, não se consegue acesso à área a ser restaurada.

O sucesso do tratamento da recessão gengival não se deve apenas ao nível de recobrimento radicular alcançado, mas também a satisfação do paciente. ${ }^{(13)}$ Logo, dentro das limitações (tipo de defeito), pode-se considerar bem sucedido o tratamento do caso relatado, pois, além dos resultados clínicos, o paciente relatou melhora na hipersensibilidade dentinária e satisfação com o resultado estético final.

A recessão gengival com abrasão cervical pode ser tratada com sucesso combinando a restauração do defeito com o recobrimento radicular, usando-se resina composta microparticulada, material biocompatível e de excelência estética, e enxerto de tecido conjuntivo, técnica de alta previsibilidade em recessões classe I e II de Miller, desde que estejam controlados os fatores etiológicos. Contudo, são necessários estudos clínicos controlados longitudinais para confirmar esses resultados.

\section{REFERÊNCIAS}

1. Löe H, Anerud A, Boysen H. The natural history of periodontal disease in man: Prevalence, severity, and extent of gingival recession. J Periodontol 1992;63:489-495.

2. Alkan A, Keskiner I, Yuzbasioglu E. Connective tissue grafting on resin ionomer in localized gingival recession. J Periodontol 2006;77:1446-1451.

3. Marini M, Greghi SL, Passanezi E, Sant' ana A. Gingival recession: Prevalence, extension and severity in adults. J Appl Oral Sci 2004;12(3):250-5. 
4. Santamaria M, Suaid F, Nociti FH Jr., Casati M, Sallum AW, Sallum EA. Periodontal surgery and glass ionomer restoration in the treatment of gingival recession associated with a non-carious lesion: Report of three cases. J Periodontol 2007;78:1146-1153.

5. Piotrowski B, Gillete W, Hancock E. Examining the prevalence and characteristics of abfractionlike cervical lesions in a population of U.S. veterans. JADA 2001;132:1694-1701.

6. Lucchesi J, Santos VR, Amaral C, Perruzo DC, Duarte P. Coronally positioned flap for treatment of restored root surfaces: A 6-month clinical evaluation. J Periodontol 2007;78:615623.

7. Zucchelli G, Testori T, De Sanctis M. Clinical and anatomical factors limiting treatment outcomes of gingival recession: A new method to predetermine the line of root coverage. $\mathrm{J}$ Periodontol 2006;77:714-721.

8. Martins T, Bosco A, Nóbrega F, Nagata M, Garcia V, Fucini S. Periodontal tissue response to coverage of root cavities restored with resin materials: A histomorphometric study in dogs. J Periodontol 2007;78:1075-1082.

9. Gray J. When not to perform root coverage procedures. J Periodontol 2000;71:1048-1050.

10. Dragoo MR. Resin-ionomer and hybrid-ionomer cements: Part II, human clinical and histologic wound healing responses in specific periodontal lesions. Int J Periodontics restorative Dent 1997;17:75-87.

11. Santos VR, Lucchesi J, Cortelli S, Amaral C, Feres M, Duarte P. Effects of glass ionomer and microfilled composite subgingival restorations on periodontal tissue and subgingival biofilm: A 6-month evaluation. J Periodontol 2007;78:1522-1528.

12. Padbury A Jr., Eber R, Wang HL. Interactions between the gingival and the margin of restorations. J Periodontol 2003;30:379-385.

13. Bouchard P, Malet J, Borghetti A. Decision-making in aesthetics: Root coverage revisited. Periodontol 2000 2001;27:97-120.

14. Chambrone L, Chambrone D, Pustiglioni FE, Chambrone LA, Lima LA. Can subepithelial connective tissue grafts be considered the gold standard procedure in the treatment of Miller Class I and II recession-type defects? J Dentistry 2008;36: 659-671.

15. Campos GV, Bittencourt S, Sallum AW, Nociti FH Jr., Sallum EA, Casati MZ. Achieving primary closure and enhancing aesthetics with periodontal microsurgery. Pract Proced Aesthet Dent 2006;18(7):449-454. 